Research Article

\title{
SWOT Research on the Development of Rural Tourism E-Commerce System under the Background of Big Data Era
}

\author{
Minglong Zhao, ${ }^{1}$ Jing Zhou $\mathbb{D}^{1},{ }^{1}$ and Jin $\mathrm{Mu}^{2}$ \\ ${ }^{1}$ College of Economics and Management, Shenyang Agricultural University, Shenyang 110000, Liaoning, China \\ ${ }^{2}$ College of Marxism, Shenyang Agricultural University, Shenyang 110000, Liaoning, China \\ Correspondence should be addressed to Jing Zhou; zhoujinglunwen@163.com
}

Received 20 August 2021; Revised 20 September 2021; Accepted 28 September 2021; Published 5 November 2021

Academic Editor: Sang-Bing Tsai

Copyright (c) 2021 Minglong Zhao et al. This is an open access article distributed under the Creative Commons Attribution License, which permits unrestricted use, distribution, and reproduction in any medium, provided the original work is properly cited.

Economic development has gradually made tourism one of the most common options for people's leisure and entertainment. The fast-paced life and heavy pressure in the city have made the relaxed and comfortable rural tourism sought after by many people. In our country, many villages have rich tourist attractions and unique cultural heritage, but they have not been fully developed due to information obstruction. Now, the advancement of Internet technology has made e-commerce, an emerging trade method, more closely related to rural tourism. Based on the background of big data, this paper has launched a research on the SWOT analysis of the development of rural tourism e-commerce system. Starting from the advantages, disadvantages, opportunities, and threats of the tourism e-commerce system, this paper discusses the necessity of combining rural tourism and e-commerce platforms in the Internet era, combining various internal and external conditions. From the perspective of the e-commerce system, all kinds of special features in the countryside can be transformed into product selling points on the platform to attract tourists, and the promotion of tourism revenue through the platform can further promote the continuous improvement of the rural tourism industry and form a virtuous circle. According to our data from the China Tourism Administration and related tourism statistics, the number of rural tourists in my country has increased from 630 million in 2011 to 3.13 billion in 2019, and the increase in rural tourism revenue has also reached 4.3 times. In order to prevent the rural backward marketing strategy from hindering the development of rural tourism, the introduction of a tourism e-commerce platform is a very necessary choice.

\section{Introduction}

As the market economy develops, the marriage of rural travel and e-commerce has become an indispensable trend. The growing popularity of information society has made people pay more interest to the ease and relaxation of tourism. Traditional tourism methods can hardly meet the new requirements of tourism for the tourism market. Under the background of the era of big data, people can collect all kinds of information they need only through the Internet. The tourism e-commerce system can provide a lot of help for the development of rural tourism. It can not only improve the efficiency of information communication between suppliers and customers but also enable tourism companies to understand market dynamics more quickly and make timely business strategy adjustments. The use of e-commerce platforms to display information on rural tourism products can also better attract tourists to purchase products and broaden sales channels while reducing costs.

In foreign countries, many scholars have conducted research on the development of e-commerce and tourism in the information age. Sambhanthan has conducted research on e-commerce network promotion. He focused on the application of information systems in tourism promotion and focused on the organizational factors that affect e-commerce strategies. During the research process, he randomly selected five hotels, conducted a structural analysis of their network promotion plan, and finally concluded an e-commerce strategy promotion outline. From the experimental results, the business strategy he proposed has indeed achieved certain results in promoting tourism promotion, but on the whole, the strategy does not fully combine the 
characteristics of local tourism competition to give targeted opinions [1]. The application of e-commerce in the tourism industry not only creates new competitive advantages but also brings certain challenges. Ermakova took a German travel website as an example to discuss the privacy violation mechanism in e-commerce. He conducted research on 50 highly visited travel websites, analyzed the number and types of required and optional data for registration, and further checked the level of personal data collected on the platform background. From the results, most websites maintain a certain cooperative relationship with third-party platforms, and the general terms and conditions have led to a lack of protection of user privacy to a certain extent. However, due to the lack of time span and data samples in related research, the results of these experiments are difficult to be convinced by the public [2].

When compared with developed countries, the rise of domestic e-commerce and rural tourism is relatively late, the rise of domestic tourism is after the reform and opening up, the start of e-commerce is a little later, but the momentum of development over the years should not be underestimated. The advancement of information technology has created excellent conditions for the development of e-commerce, and the integration of e-commerce and tourism has further improved the convenience of tourism services. Song conducted a comprehensive evaluation of the e-commerce performance of small- and medium-sized tourism companies based on resources. During the investigation, he collected tourism products and promotion programs provided by a large number of small- and medium-sized tourism companies in 10 commonly used e-commerce platforms. From the data analysis results, the company's marketing strategy, e-commerce platform, and user traffic of travel websites will directly affect the ticket sales of tourist attractions. But on the whole, his research mainly focuses on some urban scenic spots or popular attractions, because in many rural tourist attractions, the network communication infrastructure is not perfect, and the villagers' low scientific and technological information literacy makes them cooperate with e-commerce platforms [3].

The investigation in this paper focuses on the technologies and methods used in the rural tourism e-commerce system, which includes e-commerce system, data mining technology, information recommendation technologies, and clustering algorithms, from the introduction. In the context of big data, the background of the platform development and database design of the rural travel electronic commerce system are introduced. In conjunction with the SWOT analysis method, the strengths, disadvantages, opportunities, and threats of the e-commerce system development are addressed in great detail.

\section{Technology and Method of Rural Tourism Electronic Commerce System}

2.1. Tourism E-Commerce System. With the development of international trends, with the increasing popularity of the Internet, China can see ubiquitous e-commerce applications in almost all fields, and rural tourism is of course no exception. Compared with other industries, rural tourism e-commerce started late. It was not until the advent of the era of big data that people's work, life, and travel patterns had undergone earth-shaking changes, which also opened up new horizons for the development of rural tourism. Through big data, people can more intuitively understand the facilities of places they want to visit. With the development of technology, people can even directly see tourist destinations through digitization $[4,5]$.

From the perspective of the components of travel e-commerce, travel information is the most basic resource, and the evolution of e-commerce technology provides support for travel information management. The tourism e-commerce system can integrate cross-platform and crosstemporal tourism information to build a comprehensive and finely divided tourism information database [6]. At the same time, tourism companies can provide 24-hour, uninterrupted service during holidays and a global marketing coverage scale, which greatly enhances the flexibility and versatility of the tourism industry's marketing model. Tourism e-commerce technology can provide real-time response and provide feedback to users' suggestions and opinions for the first time, which improves user experience [7]. At the same time, the information in the tourism information database can be updated promptly and quickly to avoid obsolescence. In response to new changes in the market, the e-commerce system can also collect and process very quickly and adjust the marketing model according to the changes [8]. Figure 1 shows the system structure of the rural tourism e-commerce system.

2.2. Data Mining Technology. There are processes in data mining including data preparation, data mining, and final description of the results. When we use data mining techniques, we need to organize these steps, sequence them, and repeat these processes often afterward [9]. Collaborative filtering technology is the first proposed, the most in-depth research, and the most widely used personalized recommendation technology. The basic idea is that people are divided into groups, and people who often buy the same products have similar user preferences and similar information needs $[10,11]$.

2.2.1. Collaborative Filtering Algorithm. For the purpose of measuring the resemblance between speakers, the collaborative filtering algorithm usually uses a matrix to represents the user evaluations; a texture containing rows and columns is constructed to represent the users and the rated items. For user $i$ and user $j$, their scores for the item are $\left(t_{i 1}, t_{i 2}, t_{i 3}, \ldots, t_{i n}\right),\left(t_{j 1}, t_{j 2}, t_{j 3}, \ldots, t_{j n}\right)$, respectively, and $\operatorname{sim}(i, j)$ is used to measure their similarity.

The similarity between users $i, j$ satisfies the formula

$$
\operatorname{sim}(i, j)=\cos (\stackrel{\oplus}{i}, \stackrel{\rho}{j})=\frac{\stackrel{\omega}{i}, j}{(\|\stackrel{\oplus}{i}\| *\|\rho j\|)}
$$

According to the correlation similarity of the collaborative filtering algorithm, $I_{i j}$ can be defined as the set of 


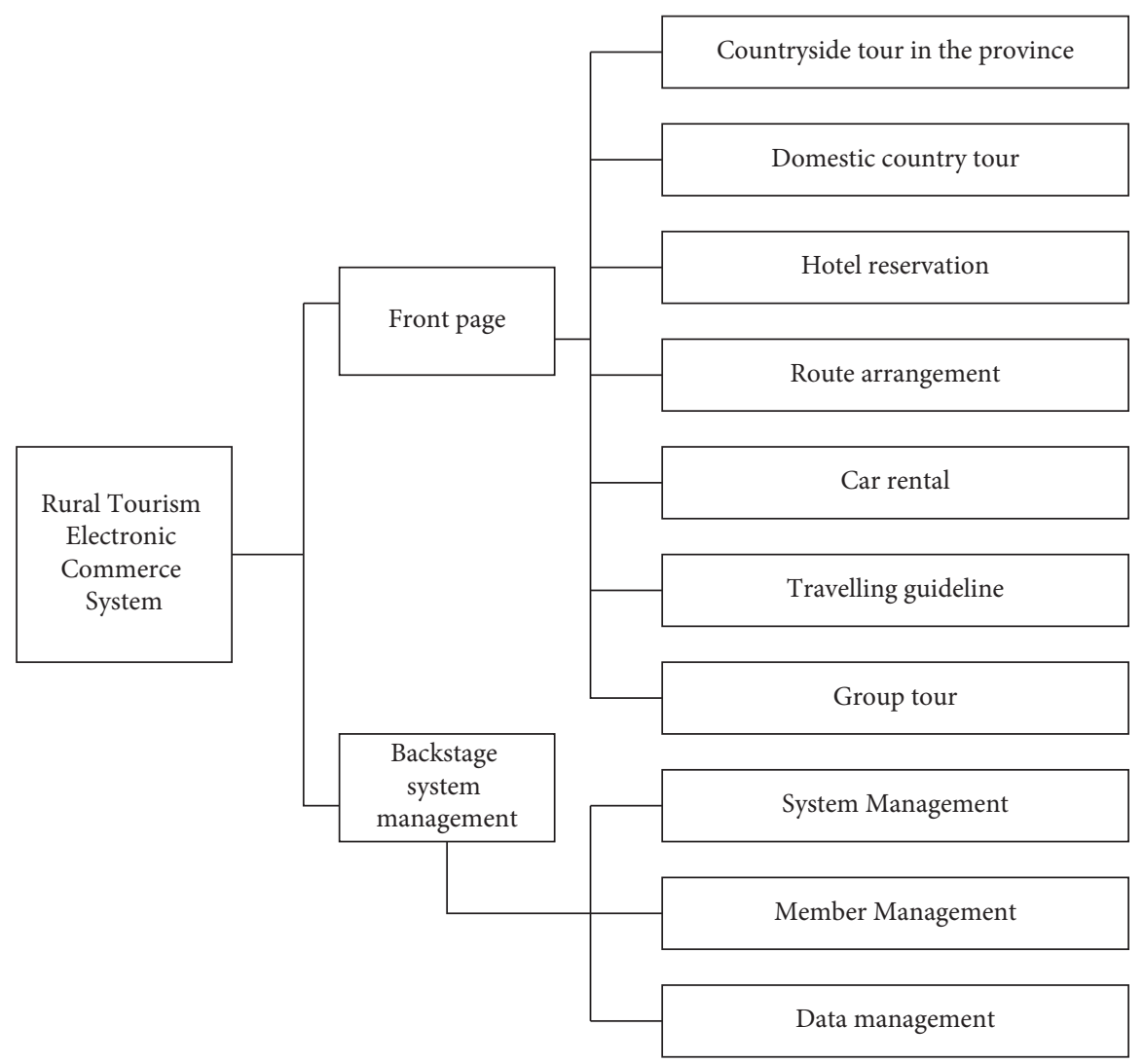

FIGURE 1: System structure of rural tourism e-commerce system.

items scored by user $i$ and user $j$, and the $\operatorname{similarity} \operatorname{sim}(i, j)$ between them satisfies

$$
\operatorname{sim}(i, j)=\frac{\sum_{c \in I_{i j}}\left(t_{i, c}-\bar{t}_{i}\right)\left(t_{j, c}-\bar{t}_{j}\right)}{\sqrt{\sum_{c \in I_{i j}}\left(t_{i, c}-\bar{t}_{i}\right)^{2}} \sqrt{\sum_{c \in I_{i j}}\left(t_{j, c}-\bar{t}_{j}\right)^{2}}} .
$$

The modified cosine similarity is essentially based on subtracting the user's average rating of the item, which improves the calculation accuracy to a certain extent. Among them, the collection of items rated by the user is $I_{i}, I_{j}$, and then $\operatorname{sim}(i, j)$ satisfies

$$
\operatorname{sim}(i, j)=\frac{\sum_{c \in I_{i j}}\left(t_{i, c}-\bar{t}_{i}\right)\left(t_{j, c}-\bar{t}_{j}\right)}{\sqrt{\sum_{c \in I_{i}}\left(t_{i, c}-\bar{t}_{i}\right)^{2}} \sqrt{\sum_{c \in I_{j}}\left(t_{j, c}-\bar{t}_{j}\right)^{2}}} .
$$

After completing the above steps, you can get the neighbors closest to the target user, and then you need to make corresponding product recommendations for them [12]. Suppose NC is the nearest neighbor set of user C, and $t_{c 1}$ is the predicted score of the project. The calculation formula meets

$$
P_{c, i}=\overline{t_{c}}+\frac{\sum_{m \in N_{c}}(c, n)\left(t_{n, i}-\bar{t}_{n}\right)}{\sum_{m \in N_{c}}(|\operatorname{sim}(c, n)|)} .
$$

2.2.2. Improved Collaborative Filtering Algorithm. When traditional collaborative filtration algorithms perform user gathering mining, they categories users based on their ratings of each project. Such classification is easy to interpret and reasonable since recommendation results acquired through mutual assistance between and among similar users are identical for each comparison [13]. But on the other hand, the user-based collaborative recommendation also has certain shortcomings, so this paper has made appropriate improvements to it to better improve the accuracy of data mining.

Aiming at the problems in traditional collaborative filtering algorithms, this paper proposes a collaborative filtering algorithm based on user preferences (UPCF) [14]. The algorithm is based on an implicit scoring method, which can complete data collection during the user's browsing of tourism products and give objective and accurate recommendations.

Set the average time value of PageLink ${ }_{j}$ to $\overline{t_{j}}$, the time set of user $i$ and user $k$ 's common interest in PageLink ${ }_{j}$ is $p_{j k}$, and $\operatorname{sim}(i, k)$ is the similarity value of user $i$ and user $k$ and satisfies the formula

$$
\operatorname{sim}(i, k)=\frac{\sum_{j \in p_{j k}}\left(t_{i j}-\overline{t_{j}}\right)\left(t_{k j}-\overline{t_{j}}\right)}{\sqrt{\sum_{j \in p_{j k}}\left(t_{i j}-\overline{t_{j}}\right)^{2}} \sqrt{\sum_{j \in p_{j k}}\left(t_{k j}-\overline{t_{j}}\right)^{2}}} .
$$


2.3. Information Recommendation Technology. The essence of information retrieval technology is to retrieve information that is valuable to users from a database containing a large amount of data in accordance with user needs [15]. Take the rural tourism e-commerce system as an example. When users use the e-commerce platform, they will input corresponding keywords in combination with their ideal travel locations. The preestablished product information index catalog in the e-commerce system database can help users quickly get the information they want [16]. If information retrieval basically works around a static information repository, then information filtering is a filtering work for dynamic information. In practical applications, information filtering has high requirements for immediacy, which can help users remove worthless information. On the whole, although the two methods of achieving technology are similar, their work goals are quite different [17].

2.3.1. Recommendation Based on Association Rules. With the in-depth research on the mining of association rules, people have gradually gained a new understanding of customers' purchasing behavior. From another perspective, recommendations based on association rules can also be of great help in guiding business decisions [18]. In actual work, you can choose the appropriate one as the auxiliary tool of the system from three common association rules based on the category of the variables processed in the rule, the abstraction level of the data in the rule, and the data dimension involved in the rule [19].

Define the association rule mining data set $D=\left\{t_{1}, t_{2}, \ldots, t_{n}\right\}, I$ is the collection of all items in $D$, and each transaction $t_{k}=\left\{i_{x}, i_{y}, \ldots, i_{z}\right\}(k=1,2, \ldots, n)$ is a subset of I [20]. Then the support in data set $D$ is

$$
\operatorname{support}\left(I_{1}\right)=\frac{\left\|\left\{t \in D \mid I_{1} \subseteq t\right\}\right\|}{\|D\|} .
$$

2.3.2. Recommendations Based on Collaborative Filtering. Compared with the traditional recommendation method, it is also applicable to unstructured data, which is a significant advantage of collaborative filtering. For items with incomplete and inaccurate keyword extraction such as videos, pictures, and music, collaborative filtering recommendations can be recommended based on the interest preferences of neighboring user groups [21]. On the whole, collaborative filtering has a relatively good performance when recommending some complex products and it is difficult to extract product feature attributes.

When the user visits the website, the online recommendation module of the recommendation system filters the current transaction from the server's log data. After user identification processing, combined with the current session and mode set, it provides the user with real-time recommendations. The recommendation set includes super links, advertisements, texts, goods, and services [22]. Given a thing cluster $t c$ and threshold $\mu$, its calculation method using feature ur $_{t c}$ satisfies

$$
\operatorname{ur}_{t c}=\left\{\left\langle p, \text { weight }\left(p, \operatorname{ur}_{t c}\right)\right\rangle \mid p \in P, \text { weight }\left(p, \operatorname{ur}_{t c}\right) \geq \mu\right\},
$$

where weight $\left(p, \operatorname{ur}_{t c}\right)$ is the weight $\operatorname{ur}_{t c}$ of page $p$ in the use feature and its calculation formula meets

$$
\text { weight }\left(p, \operatorname{ur}_{t c}\right)=\frac{1}{|t c| \sum_{t \in t c} u w(p, t)} .
$$

\subsection{Clustering Algorithm and Data Matrix}

2.4.1. Clustering Algorithm. Agglomeration process is the process of classifying data objects into several separate groups or climates. One should note that clusters were collections of objects, so the objects in each one were somewhat similar, and the objects in different clusters were also different [23]. The fundamental concept of the agglomeration algorithm is classification; however, it differs from classification in that it is more of a data-driven study method to form up the classes.

The input of cluster analysis can be represented by an ordered pair $(X, s)$ or $(X, d)$, where $X$ represents a sample and $s$ and $d$ represent indicators of similarity or difference in the sample. The output data classification result $C=\left\{C_{1}, C_{2}, \ldots, C_{k}\right\}$, where $C_{i}(i=1,2, \ldots, k)$ is a subset of $X$ and meets the following conditions:

$$
\begin{aligned}
C 1 \cup C 2 \cup \cdots \cup C k & =X, \\
C 1 \cap C 2 & =\Phi, \quad i \neq j .
\end{aligned}
$$

Given a data set of $n$ data objects, divide the data into $k$ clusters to minimize the objective function. The algorithm needs to meet the following two conditions at the same time: each data object belongs to a unique cluster; each cluster has at least one data object. Among them, the $k$-means algorithm and $k$-medoids algorithm are more commonly used partition clustering algorithms [24].

The $k$-average algorithm first needs to randomly select $k$ points as the initial centroid of the $k$ classes and then calculate the distance between the remaining objects and each centroid and assign each object to the class with the closest distance and then calculate the centroid of each class. This process is repeated until the objective function converges. Set the sum of the average errors of all objects in the database as $E, p$ as the data object, and $c_{i}$ as the average value of $C_{i}$, and then the objective function satisfies the formula

$$
E=\sum_{i=1}^{k} \sum_{p \in C_{i}}\left\|p-c_{i}\right\|^{2}
$$

2.4.2. Data Matrix. Two data structures are mainly used to cluster users: data matrix and difference degree matrix. Each row of the data matrix represents an object, and each column represents each attribute of this object. There are a total of $n$ objects, and each object has $p$ attributes. The form of representing objects and attribute values as a matrix can satisfy 


$$
\left[\begin{array}{lll}
x_{11} & x_{1 k} & x_{1 p} \\
x_{i 1} & x_{i k} & x_{i p} \\
x_{n 1} & x_{n f} & x_{n p}
\end{array}\right] .
$$

The difference degree matrix stores the difference between two objects. Generally, the difference is measured by distance. Among them, $d(i, j)$ represents the difference between the object $i, j$; the closer the two are, the smaller the value of $d(i, j)$ is, and vice versa. The difference degree matrix is an $n \times n$-order matrix as shown as follows:

$$
\left[\begin{array}{ccccc}
0 & & & & \\
d(2,1) & 0 & & & \\
d(3,1) & d(3,2) & 0 & & \\
\vdots & \vdots & \vdots & 0 & \\
d(n, 1) & d(n, 2) & \cdots & \cdots & 0
\end{array}\right] .
$$

In the travel e-commerce recommendation system, the user's interest can be obtained through the user's behavior instead of the user's evaluation of the product, and the user's interest degree matrix for clustering or collaborative filtering recommendation can be established [25].

Set user behavior to $v$, and give it a weight $C_{v}$ in the range of $0-1 ; F=\{S, B, O\}$ is the behavior set. $P_{i j}$ represents customer $i$ 's interest in $j$-type tourism products, and it satisfies the expression

$$
P_{i j}=\sum_{v \in F} C_{v} P_{i j}^{v}
$$

Among them, the calculation of $P_{i j}^{v}$ satisfies the formula

$$
P_{i j}^{v}=\frac{T_{i j}^{v}-\min _{1 \leq j \leq n} T_{i j}^{v}}{\max _{1 \leq j \leq n}\left(T_{i j}^{v}\right)-\min _{1 \leq j \leq n}\left(T_{i j}^{v}\right)} .
$$

The user's interest is often variable. The customer's recent behavior can better reflect the customer's current interest, while the historical behavior may be the user's historical interest, but not a good reflection of the current interest. We use the progressive forgetting method to measure the changes in user interest over time. The progressive forgetting function $h(t)$ satisfies the formula

$$
h(t)=m \bullet\left(\frac{t-t_{\min }}{t_{\max }-t_{\min }}\right)^{2}+1-m,
$$

where $m$ represents the past forgetting coefficient and $t_{\min }, t_{\max }$ represent the earliest and latest time to visit the page. Use the past function to adjust the number of times $T_{i j}^{v}$ of the behavior $v$ of type $j$ tourism products by user $i$ in a certain time area, and the adjusted number of clicks can be obtained:

$$
T_{i j}^{v}=\sum_{t_{\min }}^{t_{\max }} d_{i j}^{v}(t) h(t) .
$$

Finally, the interest degree matrix of user products can be obtained:

$$
U=\left[\begin{array}{cccccc}
P_{11} & P_{12} & \cdots & P_{1 j} & \cdots & P_{1 n} \\
P_{21} & P_{22} & \cdots & P_{2 j} & \cdots & P_{2 n} \\
\cdots & \cdots & \cdots & \cdots & \cdots & \cdots \\
P_{i 1} & P_{i 2} & \cdots & P_{i j} & \cdots & P_{i n} \\
\cdots & \cdots & \cdots & \cdots & \cdots & \cdots \\
P_{m 1} & P_{m 2} & \cdots & P_{m j} & \cdots & P_{m n}
\end{array}\right] .
$$

Among them, $m$ is the number of users, and $n$ is the product category of travel e-commerce. Using the user interest matrix to calculate the degree of dissimilarity between users and perform cluster analysis on users, users with similar travel goals can be grouped together, and users with different travel goals can be divided into many different classes [26, 27].

\section{Experiment of Rural Tourism E-Commerce System Based on Big Data}

3.1. Experimental Background. Before developing the experimental system, this paper conducted a thorough investigation of the current situation of the tourism e-commerce system and finally found that most of the tourism e-commerce platforms on the market have more or less various problems. Among them, the most obvious problem is that the limitations of technology cause many obstacles to the development and maintenance of the website. Based on big data, this paper developed a rural tourism e-commerce system, combined with the actual needs of tourism e-commerce, and explained the system's experimental design from front-end technology, back-end technology, and cross-platform technology.

\subsection{Experimental System Design}

3.2.1. System Design Principles. When developing the rural tourism e-commerce system, this paper adheres to the design principles of practicability, advancement, scalability, standardization, and safety. The implementation of the actual work will provide guidance for the system design. Therefore, in the selection and design of the scheme, we should pay attention to the support for practicability and advancement and effectively meet the actual needs of the design and development of the tourism e-commerce system. At the same time, under the principle of practicality, we should weigh and choose the current more advanced technologies with good development trends to ensure that the system can still keep up with the rapid development of e-commerce technology in the next few years. When designing the system, this paper uses the Spring MVC $+\mathrm{Hi}-$ bernate framework, according to the clear division of business layer, presentation layer, and logic layer, so that the software is easy to maintain and expand and redevelop. In addition to considering the principle of standardization and openness from the perspective of the technical route, this system also realizes the discovery and invocation of heterogeneous platform data communication and web services 
through web service technology, which enhances the degree of openness of the system.

3.2.2. System Implementation Model. In the system implementation model, web server, data server, and APP server are the foundations for the realization of system functions. The back-end server can continuously provide data storage and recovery services and conduct online payment call management with the APP server. The APP server handles the communication between the mobile client or third-party online payment and the back-end database server. The web server publishes the web application built by the system to the browser.

3.2.3. Logical Architecture Design. The travel e-commerce system is constructed according to the MVC model, the original MVC hierarchy is customized and refined, and the system is divided into user layer, presentation layer, business logic layer, and data storage layer. The user layer handles the role division of the entire system. In the travel e-commerce system, the super administrator has the highest level of management authority and can manage all users in the system. The presentation layer is responsible for system page display, mainly controlling page jumps and data presentation. With the support of the business logic layer, the user interface requirements are fulfilled. The business logic layer is the business logic implementation layer of the entire travel e-commerce system. This layer stores the data returned by the presentation layer and restores the processed or stored data to the page. This is the business processing core of the entire system. The function of the data storage layer is to promote data flow interaction between system data and database and complete data storage and backup. At the same time, it provides data table addition, deletion, modification, and query interfaces, and the system data is persistently backed up to the database table.

3.3. Experimental Database Design. The data storage layer is the data support of the entire travel e-commerce system and is responsible for system database backup and restoration. In the construction of the data model, the logical data model (LDM) establishes a database table for the function to be realized. In the travel e-commerce system designed in this paper, user information table, user permission table, scenic spot information table, order information table, and payment information table together constitute the travel e-commerce system database. Table 1 is the database table of the tourism e-commerce system.

The background development process uses HQL language to create tables for the database. Developers are not exposed to the database query language but write the database editing operations as Java plus classes. According to business requirements, add, delete, modify, and query data table records by operating related classes.

\section{SWOT Research on the Development of Rural Tourism E-Commerce System Based on Big Data}

\subsection{Advantages of the Development of Rural Tourism E-Commerce System}

4.1.1. Rich Rural Tourism Resources. The development of the rural tourism e-commerce system means that modern Internet technology will be more applied to the production, marketing, and management of rural tourism, and tourism e-commerce will gradually become an important part of the development of rural information. When rural tourism is displayed as a product in an e-commerce platform, tourists can conduct online consultations and transactions to form a deep understanding of the scenic spot. Based on this thinking, this paper believes that a comprehensive rural tourism e-commerce system can perfectly cater to the new marketing strategies in the current tourism industry. For rural tourism, the biggest competitive advantage is that it has unique tourism resources and contains a profound cultural heritage. The organic combination of rural tourism and e-commerce system can enable tourists to form a deeper understanding of rural scenic spots through publicity. Table 2 and Figure 2 show the statistics of the second batch of key rural tourism villages in my country.

As can be seen from Figure 2, the 680 key tourism villages released by the country this time are spread across all provinces and cities across the country. Hubei Province has the largest number, with 27 villages selected; Shanghai and Tianjin, which have the least number, also have 11 villages each. In addition, Jiangsu, Zhejiang, Fujian, Guizhou, and Jiangxi also have 25 or more villages that have become key tourist villages.

There are tens of thousands of characteristic tourism villages with rich resources all over our country, and the reason why these more than 600 villages can stand out and be selected as key tourism villages is due to the key decisionmaking of rural tourism enterprises and the pace of the times. Marketing strategy has a very direct relationship. Compared with the fast-paced and prosperous cities, the countryside usually gives people a more peaceful and soothing feeling. Relaxation has gradually become the main slogan of rural tourism development. The e-commerce system is essentially a sales platform. Finding products that can directly address the pain points of consumers is undoubtedly the best way to increase sales and drive a virtuous cycle of platform development. Figure 3 is a survey of the reasons why tourists travel.

It can be seen from Figure 3 that the highest proportions of people's travel plans are to appreciate natural and cultural scenery, relieve stress and improve mood, and travel with family and friends to promote interpersonal relationships. Among them, appreciation of natural scenery and link pressure add up to $76.4 \%$, and rural tourism has a very obvious competitive advantage in these two points. In summary, this paper believes that the rich rural tourism resources are not only very helpful to increase local tourism 
TABle 1: Database table of travel e-commerce system.

\begin{tabular}{lcc}
\hline Name & Data type & Notes \\
\hline User id & Int $(11)$ & Identify users, each user has a unique corresponding user id \\
User name & Varchar $(255)$ & Identify user name \\
Password & Varchar $(255)$ & User password \\
Auth id & Int $(11)$ & Identify permissions, a user has several permissions \\
Place id & Int (11) & Attraction identification, marking the only attraction \\
Desc & Text & Attraction information description \\
Order id & Int $(11)$ & Identify ID, marking the unique order \\
Number & Int (11) & Number of visitors in the order \\
Total money & Decimal & The total amount paid for the order \\
Pay id & Int $(11)$ & Identify information identification \\
User card no & Varchar $(255)$ & User payment card number \\
\hline
\end{tabular}

TABLE 2: List of second batch of national rural tourism key villages.

\begin{tabular}{|c|c|c|c|c|c|c|c|}
\hline Province & Quantity & Province & Quantity & Province & Quantity & Province & Quantity \\
\hline Beijing & 23 & Tianjin & 11 & Hebei & 24 & Shanxi & 18 \\
\hline Inner Mongolia & 15 & Liaoning & 21 & Jilin & 19 & Heilongjiang & 21 \\
\hline Shanghai & 11 & Jiangsu & 26 & Zhejiang & 26 & Anhui & 22 \\
\hline Fujian & 26 & Jiangxi & 25 & Shandong & 24 & Henan & 21 \\
\hline Hubei & 27 & Hunan & 23 & Guangdong & 22 & Guangxi & 22 \\
\hline Hainan & 16 & Chongqing & 20 & Sichuan & 23 & Guizhou & 26 \\
\hline Yunnan & 23 & Tibet & 21 & Shaanxi & 23 & Gansu & 20 \\
\hline Qinghai & 20 & Ningxia & 20 & Xinjiang & 24 & & \\
\hline
\end{tabular}

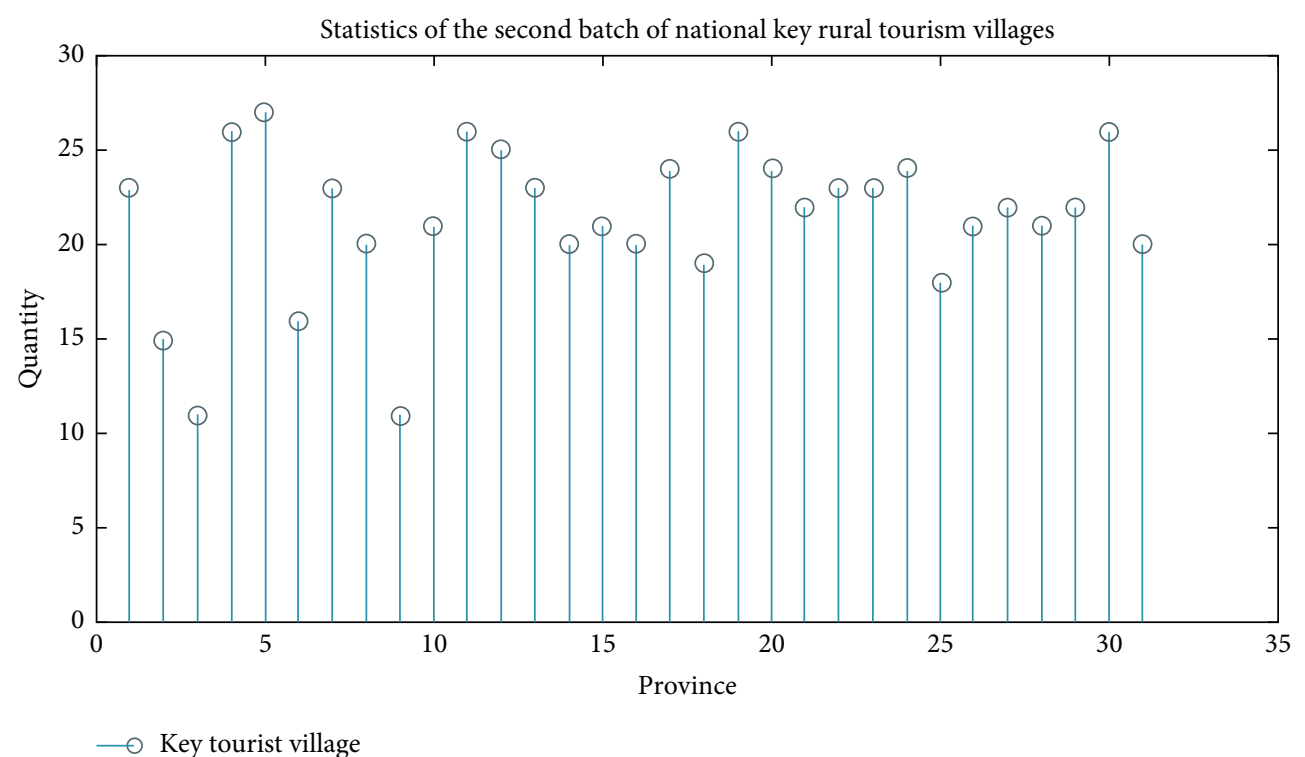

Figure 2: Second batch of key rural tourism villages.

revenue but also create advantages for promoting the development of rural tourism e-commerce systems.

4.1.2. Responsive Interaction and Personalized Service. For the tourism industry, maintaining customer relationships and providing quality services are always indispensable conditions for successful operation. If a rural tourism company can provide customers with tailor-made highquality services, then it can better gain the upper hand in the highly competitive tourism industry. Figure 4 shows the preferences of tourists in choosing travel partners in different travel locations.

It can be seen from Figure 4 that when choosing different travel locations, the proportion of tourists who choose to travel together is also different. It is worth noting that when choosing a country tour, the proportion of tourists per person is as high as $25.6 \%$. Compared with traveling with a tour group or with friends and family, tourists going to the countryside are more willing to enjoy the comfort and 


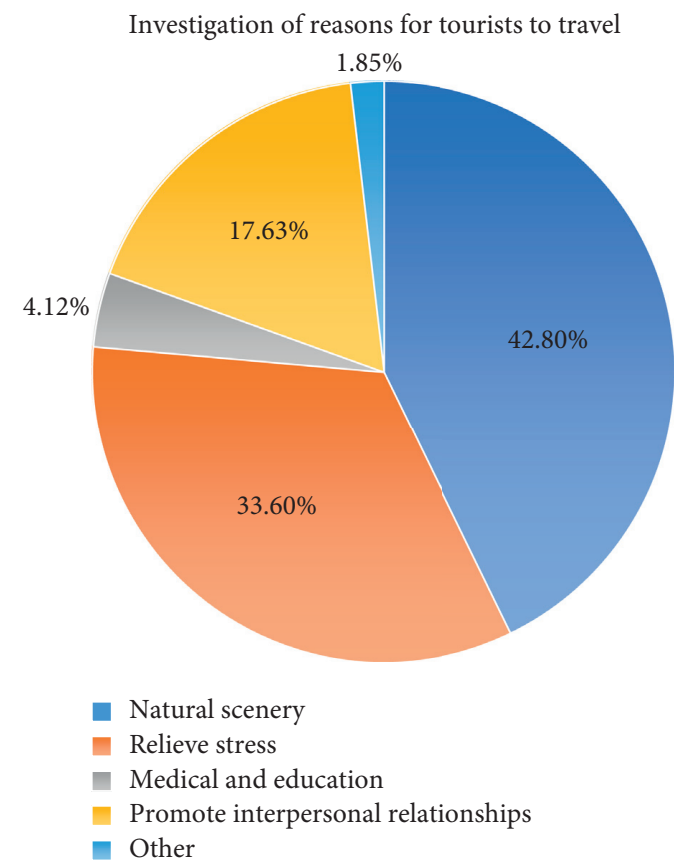

FIGURE 3: Survey statistics on the reasons why tourists travel.

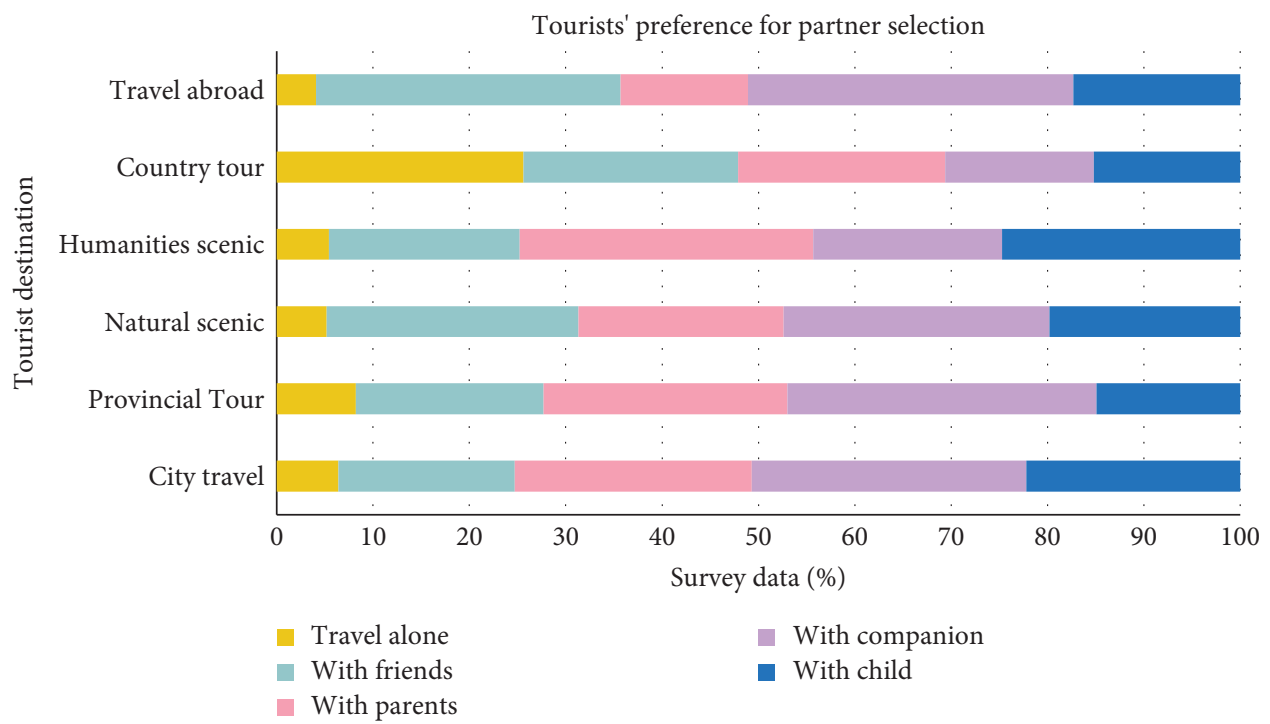

FIGURE 4: Tourists' preference for travel partners in different travel locations.

freedom of a person. For this type of tourists, what they value more is whether the travel e-commerce system can provide convenient and personalized services.

Specifically, with an e-commerce system based on big data, tourists do not need to obtain rural tourism information or transactions through travel agencies but are more inclined to use the Internet to search for rural tourism destinations on their own. Visitors' personal preferences are at the center of the era of big data. When rural tourism companies can predict the travel needs of potential customers, interact with tourists in real time, and provide tailormade travel packages, the platform can maintain long-term and stable cooperation with tourists.

\subsection{Disadvantages of the Development of Rural Tourism E-Commerce System}

4.2.1. Insufficient Development of Tourist Attractions Resources. In recent years, the domestic tourism boom has brought huge benefits to the tourism industry, but for rural tourism companies, they still face certain disadvantages if they want to develop stably. The development of tourism resources must have a certain economic foundation, but rural tourism enterprises are prone to fall into the predicament of shortage of funds. Figure 5 is the statistics on the number of tourists and income in rural tourism from 2009 to 2019. 


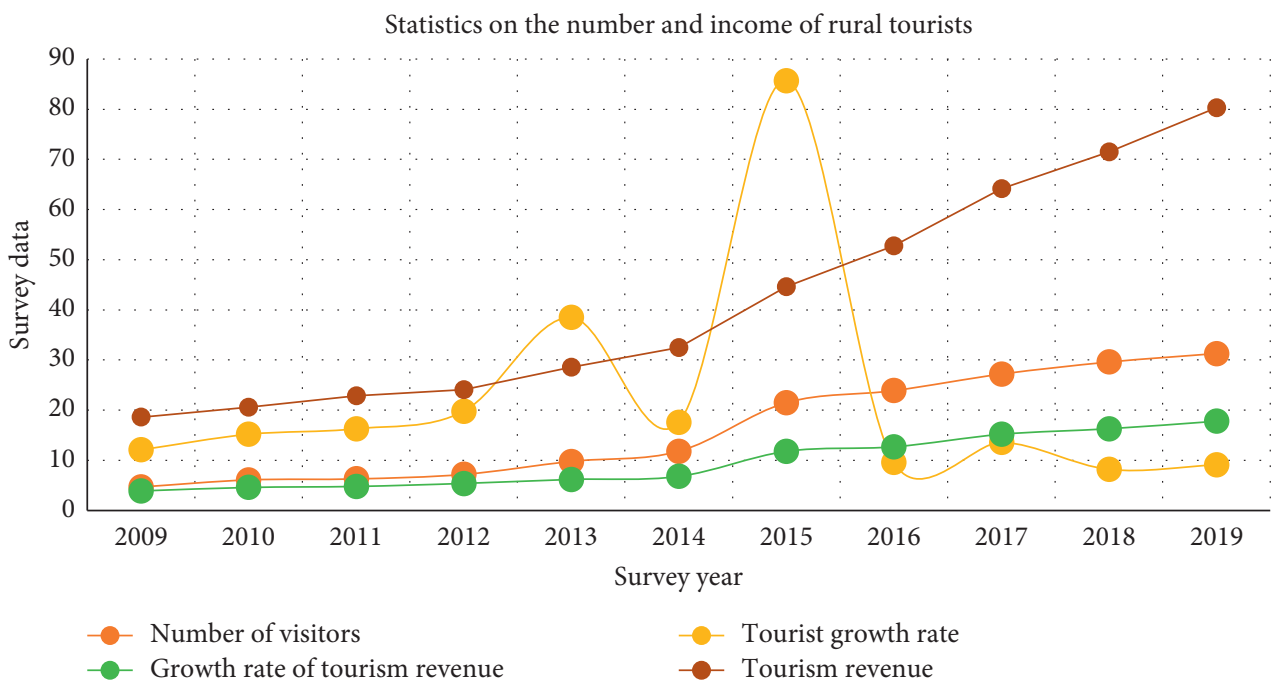

Figure 5: Statistics on the number and income of rural tourism tourists.

It can be seen from Figure 5 that the tourist reception and tourism income of my country's rural tourism industry both showed a steady upward trend from 2009 to 2019. In 2011, the number of rural tourist receptions was 630 million, and the number of rural tourist receptions in 2019 has exceeded 3 billion, which means that the number of rural tourist receptions has increased fivefold in less than ten years.

The successful development of some excellent rural tourist attractions has provided reference for many rural enterprises and governments. If you want to develop rural tourism, early investment is inevitable. With the support of national policies, sufficient and reasonable development of local tourism resources can ensure the stable development of the subsequent rural tourism e-commerce system.

4.2.2. Low Service Quality of Employees. When promoting the development of e-commerce system in rural tourism, there is an obvious disadvantage that the overall quality of rural tourism employees is relatively low. Most rural service personnel not only lack accurate knowledge of Internet technology but also have not received systematic tourism service training. Particularly for some elderly villagers, because they have lived in the countryside for a long time, there may be some friction with tourists from the city in their living habits, concepts, and communication patterns. Taking into account the lack of professional training capabilities in rural tourism enterprises, the service quality of employees will become an obvious disadvantage that restricts the development of e-commerce systems. In the simulation experiment, this paper studies the impact of adjusting the welfare benefits of talents on the development of rural tourism. Table 3 is a data table of parameter changes during regulation. Among them, M1 is talent welfare expenditure, M2 is financial support, M3 is product development rate, M4 is marketing and promotion investment, and M5 is infrastructure investment. Figure 6 shows the impact of improving talent welfare treatment on the development of rural tourism during the simulation experiment.
It can be seen from Figure 6 that, with the increase of talent capital investment, the number of people willing to engage in tourism services in the countryside will also increase. Excellent management and service personnel will stimulate the development of tourism products, coupled with creative marketing and promotion, which can bring new vitality to the informatization development of rural tourism. Aiming at the disadvantage of low-quality service personnel in the development of the tourism e-commerce system, companies can promote the development of local tourism by increasing talent welfare expenditures, in the long run, only to enhance the competitiveness of scenic spots and allow tourists to have a better travel experience. In order to form a virtuous circle, the steady progress of rural tourism can be realized.

\subsection{Opportunities and Threats for the Development of Rural Tourism E-Commerce System}

4.3.1. Opportunities for the Development of Rural Tourism E-Commerce System. In this era of big data, the popularization of the Internet constitutes the strongest cornerstone for the development of rural tourism e-commerce systems. In addition, the government's attention and support, the increasingly perfect infrastructure construction in rural areas, and the increase in residents' income have all become important opportunities for the development of tourism e-commerce platforms. Figure 7 is the survey statistics on the number of trips of Chinese people from 2013 to 2019.

It can be seen from Figure 7 that the overall enthusiasm of Chinese tourists for travel has shown an upward trend in recent years. On the whole, the number of people who never travel and only perform one to three performances in a year continues to decrease. Instead, more and more people travel four to six times a year, or more. Judging from the empirical parameters of the National Bureau of Statistics, the growth of national income will gradually change the consumption structure. One of the obvious signs is the decline in Engel's 
TABLE 3: Data table of parameter changes during regulation.

\begin{tabular}{lcccccc}
\hline Parameter & Current & Increase M1 & Increase M2 & Increase M3 & Increase M4 & Increase M5 \\
\hline M1 & 0.24 & 0.5 & 0.23 & 0.24 & 0.24 & 0.24 \\
M2 & 0.3 & 0.32 & 0.6 & 0.33 & 0.58 & 0.34 \\
M3 & 0.31 & 0.3 & 0.37 & 0.30 & 0.68 & 0.35 \\
M4 & 0.36 & 0.35 & 0.36 & 0.35 & 0.52 & 0.52 \\
M5 & 0.38 & 0.37 & & 0.54 \\
\hline
\end{tabular}

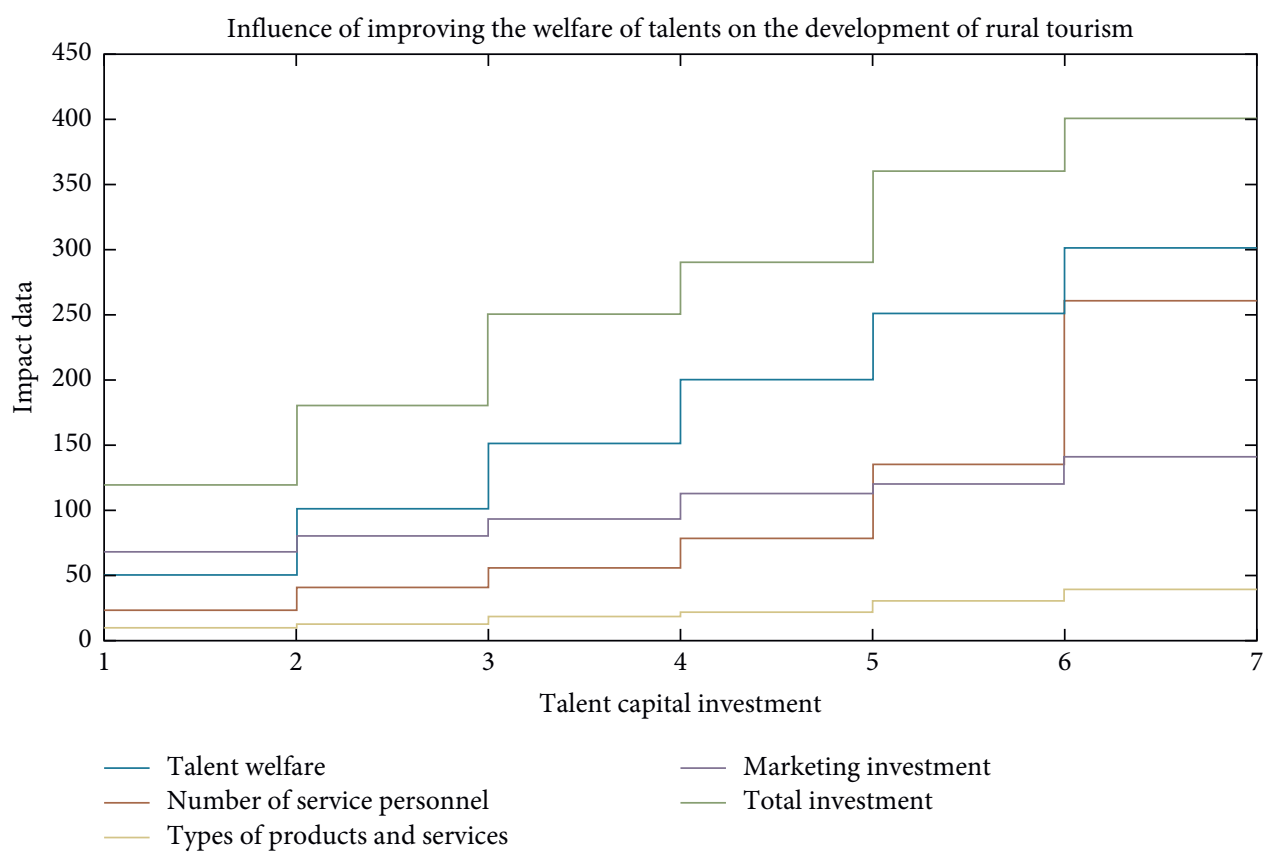

FIGURE 6: Influence of improving the welfare of talents on the development of rural tourism.

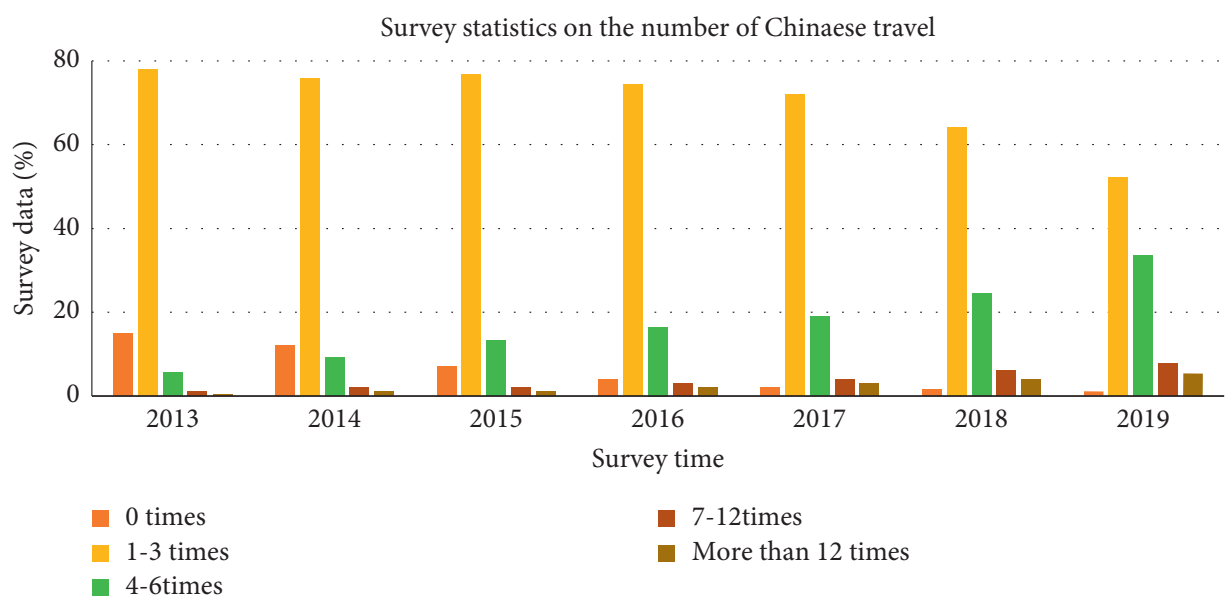

FIGURE 7: Survey statistics on the number of Chinese traveling in 2013-2019.

coefficient. People spend less on food and clothing, while consumption on housing and transportation will increase. On the whole, economic development has created better conditions for the development of rural tourism and the promotion of the progress of the rural tourism e-commerce system.
The potential of the domestic tourism consumer market has made more and more companies begin to pay attention to the development of the tourism industry. Deeply digging cultural connotations, protecting the ecological environment, and integrating tourism resources have gradually become the key goals of rural tourism development at this 
TABLE 4: Supply classification table of rural tourism products.

\begin{tabular}{lcc}
\hline & Types & Product content \\
\hline Experience class & $\begin{array}{c}\text { Farmhouse } \\
\text { Farm }\end{array}$ & $\begin{array}{c}\text { Farm and barbecue } \\
\text { Orchard; vegetable garden }\end{array}$ \\
\hline Ecological & $\begin{array}{c}\text { Ecological scenery } \\
\text { Idyllic scenery }\end{array}$ & $\begin{array}{c}\text { Farm, agronomy, and agricultural materials } \\
\text { Fruit tree, orchard, and picking }\end{array}$ \\
\hline Culture & $\begin{array}{c}\text { Ancient village } \\
\text { Folk village }\end{array}$ & $\begin{array}{c}\text { Forests, canyons, hot springs, and wetlands } \\
\text { Pastoral, tea garden, rape blossoms, and terraced fields }\end{array}$ \\
\hline \multirow{2}{*}{ Outdoor activities } & $\begin{array}{c}\text { Green lane } \\
\text { Drifting } \\
\text { Outdoor base }\end{array}$ & $\begin{array}{c}\text { Ancient villages, ancient towns, and ancient buildings } \\
\text { Festivals and folklore }\end{array}$ \\
\hline Health & & Hiking and cycling \\
\hline Revolution scenic area & Mountain climbing, fishing, rock climbing, and camping \\
\hline
\end{tabular}

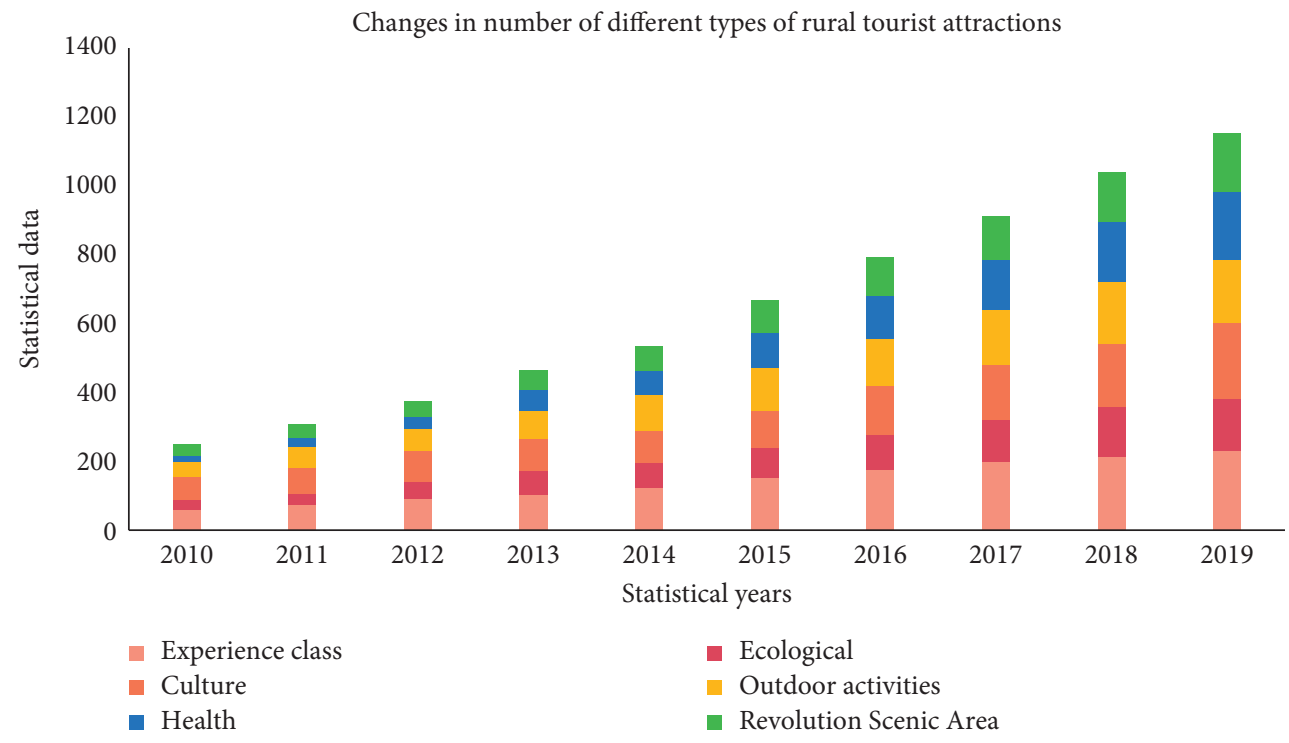

FIGURE 8: Changes in the number of different types of rural tourist attractions.

stage. Table 4 is a classification table of rural tourism product supply.

With the joint promotion of the government, enterprises, and the market, the rural tourism industry has more and more diverse product types. For tourists, they only need to enter the corresponding keywords in the e-commerce system to search for a large number of rural tourist attractions that meet their preferences and complete a series of operations such as hotel reservation, scenic ticket purchase, and travel strategy acquisition. Figure 8 is a statistical chart of the number of different types of rural tourist attractions.

It can be seen from Figure 8, over the past decade, there has been a steady growth in the number of various types of tourism services offers in China, of which experiential, cultural, and health tourism services have been favored by more and more tourists in recent years. Our country is vast, making rural tourist attractions in a variety of provinces and cities have their unique charm. Impelled by scientific development and resource aggregation, the domestic rural tourism industry is actively promoted to flourish, forming a close link with the tourism e-commerce system.

4.3.2. Threats to the Development of Rural Tourism Electronic Commerce System. It is without question that privacy is the most threatening to people's information of information security in the era of big database. As Internet technology develops, people pay more attention to the protection of online privacy. In the rural travel e-commerce system, the platforms not only record the user's cell name number and ID card but also know the user's check-in and journey in the whole process. Once user information is leaked, it will pose a great threat to personal property and even life safety. Figure 9 shows the security test results of several types of data encryption algorithms.

It can be seen from Figure 9 that the security score of the improved DES encryption algorithm has increased from 75.59 to 84.24 ; the security score of the improved OPE has increased from 80.64 to 89.65 , which is basically close to the 


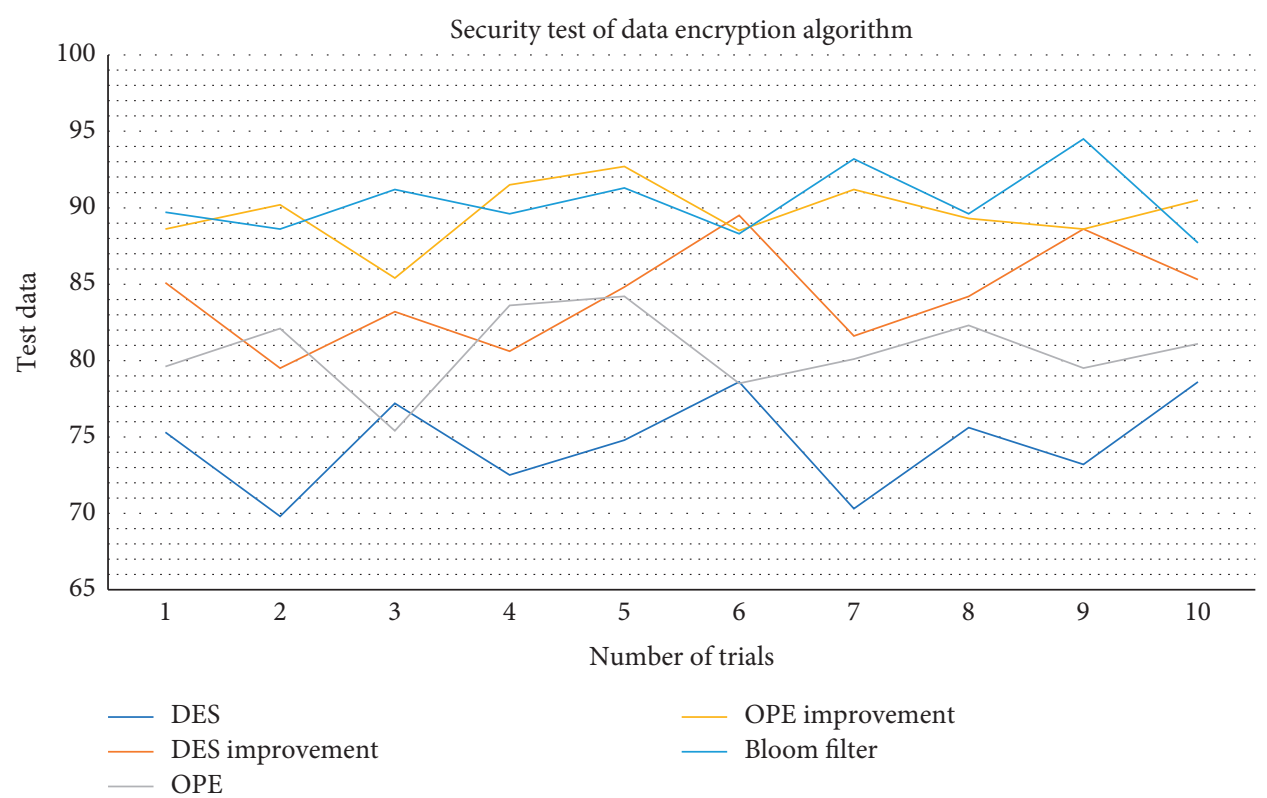

FiguRE 9: Security test results of several types of data encryption algorithms.

Bloom filter. The algorithm has a security score of 90.37 . For most users, unknown cyberattacks will keep them in a state of anxiety about information leakage. Therefore, the e-commerce platform has the responsibility to continuously consolidate the system security barrier to ensure the safety of user information and property.

\section{Conclusions}

This paper is based on the advantages and disadvantages of the development of the rural tourism e-commerce system. In the context of big data, the marketing strategies of rural tourism companies have gradually changed. More and more people realize that conforming to the tide of development of the times and establishing an effective connection between tourism and the Internet are inevitable choices for the innovation of the tourism industry. The profound cultural heritage and abundant tourism resources in the countryside provide the highest quality product guarantee for the rural tourism e-commerce system. Responsive user interaction and personalized services for tourists have further strengthened tourists' trust in the tourism e-commerce platform. In view of the low quality of rural tourism service personnel and the imperfect development of resources in some scenic spots at this stage, this paper advocates improving the welfare of talents in order to achieve a virtuous circle of tourism development.

This paper conducts research based on the opportunities and threats of rural tourism e-commerce system development. From the perspective of external conditions, the high level of government support, the continuous improvement of tourism organization, the continuous development of the tourism industry, and the continuous growth of the national economy have created favorable opportunities for the development of the e-commerce system. For the purpose of overcoming the disadvantages and threats and developing an integrated e-commerce system, the preferable solution is to establish a tripartite collaboration and development platform consisting of authorities, enterprises, and institutes. Each party should give full play to their individual roles to strengthen the connection in between rural tourism attractions and users to provide better performance for guests.

Based on the background of the era of big data, this paper conducts research on the SWOT analysis of the development of the rural tourism e-commerce system. Regardless of the industry, companies that perform well in the field of e-commerce can become leaders and winners in their specific fields, and the tourism industry is no exception. In order to cope with the contradiction between the current increase in tourism demand and the backward rural tourism marketing, it is necessary to develop a dynamic e-commerce system based on rural tourism. When analyzing the e-commerce system with SWOT, this paper explains in detail the problems in the development of tourism e-commerce from four aspects. Because of various limitations, some of the analyses can only be discussed vaguely from a macroperspective, which does not provide enough data and practical methods. E-commerce in tourism is still in a rapid development stage. We believe that, in future research, with the changes in the rapid market, e-commerce platforms will achieve a new breaking point.

\section{Data Availability}

No data were used to support this study.

\section{Conflicts of Interest}

The authors state that this paper has no conflicts of interest. 


\section{References}

[1] A. Sambhanthan and A. Good, "Strategic advantage in web tourism promotion: an e-commerce strategy for developing countries," International Journal of nformation Systems in the Service Sector, vol. 6, no. 3, pp. 1-21, 2015.

[2] T. Ermakova, A. Hohensee, I. Orlamünde, and B. Fabian, "Privacy-invading mechanisms in e-commerce - a case study on German tourism websites," International Journal of Networking and Virtual Organisations, vol. 20, no. 2, pp. 105-126, 2019.

[3] H. Song, "Comprehensive evaluation of E-commerce performance in small and medium-sized tourism enterprises: a resource-based analysis," International Journal of Multimedia and Ubiquitous Engineering, vol. 10, no. 8, pp. 139-148, 2015.

[4] Y. Liu, J. Wang, X. Shao, and J. Li, "The current situation and development trend of China's tourism e-commerce," International Journal of Tourism Sciences, vol. 18, no. 4, pp. 312324, 2018.

[5] T. J. Mapeshoane and S. Pather, "The adoption of e-commerce in the Lesotho tourism industry," The Electronic Journal of Information Systems in Developing Countries, vol. 75, no. 1, pp. 1-24, 2016.

[6] S. E. Kaplan and R. J. Nieschwietz, "A Web assurance services model of trust for B2C e-commerce," International Journal of Accounting Information Systems, vol. 4, no. 2, pp. 95-114, 2015.

[7] N. Kassim and N. Asiah Abdullah, "The effect of perceived service quality dimensions on customer satisfaction, trust, and loyalty in e-commerce settings," Asia Pacific Journal of Marketing \& Logistics, vol. 22, no. 3, pp. 351-371, 2015.

[8] J. Jeffcoate, C. Chappell, and S. Feindt, "Attitudes towards process improvement among SMEs involved in E-commerce," Knowledge \& Process Management, vol. 7, no. 3, pp. 187-195, 2015.

[9] R. Kaur and S. Singh, "A survey of data mining and social network analysis based anomaly detection techniques," Egyptian Informatics Journal, vol. 17, no. 2, pp. 199-216, 2016.

[10] R. Ma, X. Zhou, Z. Peng et al., "Data mining on correlation feature of load characteristics statistical indexes considering temperature," Proceedings of the Csee, vol. 35, no. 1, pp. 43-51, 2015.

[11] S. Zhang and K. Ren, "User preferences-based and timesensitive location recommendation using check-in data," Journal of Computer \& Communications, vol. 3, no. 9, pp. 18-27, 2015.

[12] Y. Pan, D. Wu, and D. L. Olson, "Online to offline (O2O) service recommendation method based on multi-dimensional similarity measurement," Decision Support Systems, vol. 103, no. nov, pp. 1-8, 2017.

[13] Y. Ar and E. Bostanci, "A genetic algorithm solution to the collaborative filtering problem," Expert Systems with Applications, vol. 61, no. nov, pp. 122-128, 2016.

[14] J. Zhang, Y. Lin, M. Lin, and J. Liu, "An effective collaborative filtering algorithm based on user preference clustering," Applied Intelligence, vol. 45, no. 2, pp. 230-240, 2016.

[15] J. Xu, H. Li, and C. Zhong, "Information retrieval technology," Lecture Notes in Computer Science, vol. 7675, no. 3, pp. 151-158, 2015.

[16] A. Holzapfel, B. L. Sturm, and M. Coeckelbergh, "Ethical dimensions of music information retrieval technology," Transactions of the International Society for Music Information Retrieval, vol. 1, no. 1, pp. 44-55, 2018.
[17] J. Zou and E. Kanoulas, "Towards question-based high-recall information retrieval," ACM Transactions on Information Systems, vol. 38, no. 3, pp. 1-35, 2020.

[18] G. Czibula, Z. Marian, and I. G. Czibula, "Detecting software design defects using relational association rule mining," Knowledge and Information Systems, vol. 42, no. 3, pp. 545577, 2015.

[19] J. Sahoo, A. K. Das, and A. Goswami, "An effective association rule mining scheme using a new generic basis," Knowledge and Information Systems, vol. 43, no. 1, pp. 127-156, 2015.

[20] F. Feng, J. Cho, W. Pedrycz, H. Fujita, and T. Herawan, "Soft set based association rule mining," Knowledge-Based Systems, vol. 111, no. nov.1, pp. 268-282, 2016.

[21] H. Ferdaous, F. Bouchra, O. Brahim, M. Imad-eddine, and B. Asmaa, "Recommendation using a clustering algorithm based on a hybrid features selection method," Journal of Intelligent Information Systems, vol. 51, no. 1, pp. 183-205, 2018.

[22] A. Boutet, D. Frey, R. Guerraoui, A. Jégou, and A.-M. Kermarrec, "Privacy-preserving distributed collaborative filtering," Computing, vol. 98, no. 8, pp. 827-846, 2016.

[23] Y. Guo and A. Sengur, "NECM: neutrosophic evidential c-means clustering algorithm," Neural Computing and Applications, vol. 26, no. 3, pp. 561-571, 2015.

[24] M. Capó, A. Pérez, and J. A. Lozano, "An efficient approximation to the $K$-means clustering for massive data," Knowledge-Based Systems, vol. 117, no. FEB, pp. 56-69, 2017.

[25] H. Liu, J. Wu, T. Liu, D. Tao, and Y. Fu, "Spectral ensemble clustering via weighted $K$-means: theoretical and practical evidence," IEEE Transactions on Knowledge and Data Engineering, vol. 29, no. 5, pp. 1129-1143, 2017.

[26] C.-H. Yuan, C.-H. Wu, D. Wang, S. Yao, and Y. Feng, "Review of consumer-to-consumer E-commerce research collaboration," Journal of Organizational and End User Computing, vol. 33, no. 4, 2021.

[27] L. Li and J. Zhang, "Research and analysis of an enterprise E-commerce marketing system under the big data environment," Journal of Organizational and End User Computing, vol. 33, no. 6, 2021. 